\title{
Combination of preoperative fibrinogen concentration and neutrophil-to-lymphocyte ratio for prediction of the prognosis of patients with resectable breast cancer
}

\author{
XI CAO, YIDONG ZHOU, FENG MAO, YAN LIN and QIANG SUN \\ Department of Breast Surgery, Peking Union Medical College Hospital, Peking Union Medical College, \\ Chinese Academy of Medical Sciences, Beijing 100730, P.R. China
}

Received February 27, 2020; Accepted July 30, 2020

DOI: $10.3892 / \mathrm{ol} .2020 .12061$

\begin{abstract}
Previous studies have demonstrated that the combination of high preoperative fibrinogen levels and high neutrophil-to-lymphocyte ratio (NLR) is associated with poor outcomes in various types of cancer. The present study assessed the prognostic value of a scoring system based on the combination of fibrinogen concentration and neutrophil-to-lymphocyte ratio (F-NLR) in untreated patients with resectable breast cancer (BC). The present study retrospectively analyzed 906 patients who received surgery for resectable BC. Univariate and multivariate analyses were performed to explore the association between the F-NLR score and survival status. The cut-off values for fibrinogen and NLR determined via receiver operating characteristic curve analysis were $3.21 \mathrm{~g} / 1$ and 2.20, respectively. On the basis of these cut-off values, the whole cohort was divided into three groups according to their F-NLR score: Score 2, fibrinogen $\geq 3.21 \mathrm{~g} / 1$ and NLR $\geq 2.20$; score 1 , fibrinogen $\geq 3.21 \mathrm{~g} / 1$ or NLR $\geq 2.20$; and score 0 , fibrinogen $<3.21 \mathrm{~g} / 1$ and NLR $<2.20$. The F-NLR score was significantly associated with age $(\leq 50$ years vs. $>50$ years; $\mathrm{P}<0.001)$, tumor size ( $\leq 2 \mathrm{~cm}$ vs. $>2 \mathrm{~cm} ; \mathrm{P}=0.001)$, lymph node status $(\mathrm{P}=0.029)$, TNM stage (I vs. II vs. III; $\mathrm{P}=0.002$ ) and lymphovascular
\end{abstract}

Correspondence to: Dr Qiang Sun, Department of Breast Surgery, Peking Union Medical College Hospital, Peking Union Medical College, Chinese Academy of Medical Sciences, 1 Shuaifuyuan, Dongcheng, Beijing 100730, P.R. China

E-mail: sunqiangpumc01@163.com

Abbreviations: BC, breast cancer; NLR, neutrophil-to-lymphocyte ratio; F-NLR, combination of fibrinogen concentration and neutrophil-to-lymphocyte ratio; AJCC, American Joint Committee on Cancer; HER2, human epidermal growth factor receptor 2; ROC, receiver operating characteristic; DFS, disease-free survival; OS, overall survival; AUC, area under the curve; HR, hazard ratio; NSCLC, non-small cell lung cancer; IL, interleukin; MDSCs, myeloid-derived suppressor cells

Key words: breast neoplasms, prognosis, neutrophil-to-lymphocyte ratio, fibrinogen, F-NLR score invasion $(\mathrm{P}<0.001)$. The 5-year disease-free survival (DFS) rates in the patients with F-NLR scores of 0,1 and 2 were 95.7, 87.5 and $74.0 \%$, respectively $(\mathrm{P}<0.001)$, and the 5-year overall survival (OS) rates were $97.8,90.9$ and $79.9 \%$, respectively $(\mathrm{P}<0.001)$. Furthermore, multivariate analysis demonstrated that the F-NLR score independently predicted DFS [hazard ratio (HR), 2.279; 95\% $\mathrm{CI}, 1.758-2.954 ; \mathrm{P}<0.001]$ and $\mathrm{OS}$ (HR, 2.414; 95\% CI, 1.738-3.353; $\mathrm{P}<0.001$ ). In conclusion, the preoperative F-NLR score was an independent prognostic indicator for untreated patients with resectable BC.

\section{Introduction}

Breast cancer (BC) is a major cause of mortality in women worldwide, with an estimated 2,090,000 newly diagnosed cases and 626,679 deaths in 2018 (1). Epidemiological studies have demonstrated that the incidence and mortality rates of $\mathrm{BC}$ in China are increasing (2). Westernized lifestyles and changes in fertility patterns may be a cause of the increased incidence of $\mathrm{BC}$ (3-5), and the lack of early diagnosis and effective adjuvant therapies may contribute to higher mortality.

In the 19th century, Rudolf Virchow first proposed the hypothesis that inflammation is associated with cancer (6). Since then, numerous studies have explored the relationship between them. Inflammation is now recognized as a hallmark of cancer (7), which promotes the occurrence (8), development and metastasis of cancer $(9,10)$. Various systemic inflammatory markers, including single markers, such as C-reactive protein (11), erythrocyte sedimentation rate (12), neutrophils (13), lymphocytes (10) and fibrinogen (14), and prognostic systems, such as the neutrophil-to-lymphocyte ratio (NLR) (15) and Glasgow prognostic score (16), have been demonstrated to be associated with the prognosis of different types of cancer. Studies have demonstrated that an elevated NLR is associated with poor outcomes in various types of cancer, including hepatocellular carcinoma (17), esophageal cancer (18) and BC (19). In addition, a meta-analysis of 18 studies demonstrated that high NLR is associated with shorter survival compared with low NLR in patients with BC (20).

In various malignant tumors, the coagulation system is activated and promotes tumor progression and metastasis $(21,22)$. Fibrinogen, a 340-kDa glycoprotein synthesized by the liver, 
is considered to predict the prognosis of various malignancies $(14,21)$. Elevated fibrinogen levels are associated with poor outcomes in gynaecological cancer (23), lung cancer (24) and $\mathrm{BC}(25)$.

Previous studies using a scoring system based on the combination of fibrinogen concentration and neutrophil-to-lymphocyte ratio (F-NLR) have reported that a high F-NLR score is associated with poor outcomes in different types of cancer (26-29). However, to the best of our knowledge, the prognostic value of F-NLR in BC remains unknown. Therefore, the present study aimed to investigate the prognostic role of this biomarker combination in resectable $\mathrm{BC}$.

\section{Materials and methods}

Patients. The present study retrospectively analyzed patients with resectable $\mathrm{BC}$ who received curative surgery at Peking Union Medical College Hospital (Beijing, China) between July 2012 and May 2014. The Ethics Committee on Human Research at Peking Union Medical College Hospital approved the study. Due to the retrospective nature of the present study, the committee waived the requirement for individual patient consent. The inclusion criteria were as follows: i) Female patients aged 18-80 years; ii) confirmed pathology of stage I-III BC; and iii) received radical surgery and standard adjuvant therapy, such as chemotherapy, radiotherapy, endocrine therapy, herceptin therapy. The exclusion criteria were: i) Metastatic or inflammatory $\mathrm{BC}$; ii) neoadjuvant therapy; iii) neutrophil count $>10 \times 10^{9} / 1$ for patients of untreated status; and iv) blood coagulation disorders, autoimmune disease, hematological disease or infectious disease. Finally, 906 patients were included in the present study based on the inclusion and exclusion criteria.

Clinicopathological parameters. The clinicopathological information and laboratory data for these patients were collected from their medical records. The TNM stage of $\mathrm{BC}$ was determined according to the AJCC Cancer Staging Manual (7th edition) (30). Hormone receptor status and human epidermal growth factor receptor 2 (HER2) status were assessed by immunohistochemistry according to recommendations in the American Society of Clinical Oncology/College of American Pathologists guidelines (31). When estrogen and/or progesterone receptors were determined to be positive using immunohistochemistry, the case was defined as hormone receptor-positive, whereas it was defined as negative when both hormone receptors were negative. HER2 positivity was defined as an immunohistochemistry result of $3+$ or $2+$ confirmed by further fluorescence in situ hybridization experiments. According to the hormone receptor and HER2 status, molecular subtypes of BC were categorized as follows: Luminal A-like (hormone receptor-positive, HER2-negative and $\mathrm{Ki}-67 \leq 14 \%$ ), luminal B-like (hormone receptor-positive, HER2-negative and $\mathrm{Ki}-67>14 \%$; or hormone receptor-positive and HER2-positive), HER2 (hormone receptor-negative and HER2-positive) or triple-negative (hormone receptor-negative and HER2-negative). Lymphovascular invasion was interpreted on hematoxylin and eosin staining slides of tumor specimens. When tumor cells existed in a definite endothelial-lined space, it was defined as lymphovascular invasion.

Clinical treatment and follow-up. All patients received radical BC surgery. Breast management included lumpectomy or mastectomy, and axillary management included sentinel lymph node biopsy or axillary lymph node dissection. According to the National Comprehensive Cancer Network guidelines (32), patients received standard adjuvant therapy after surgery as appropriate. Follow-up was conducted every 6 months in the 2 years after surgery and annually thereafter. The last date of observation was July 31, 2019.

F-NLR definition and evaluation. Routine blood sampling was performed 3 days before surgery to obtain the following indices: Neutrophil count, lymphocyte count and plasma fibrinogen level. The NLR was determined by dividing the neutrophil count by the lymphocyte count. The cut-off values of the NLR and preoperative fibrinogen concentration were determined using receiver operating characteristic curve (ROC) analysis. Based on the ROC analysis, the optimal cut-off values of NLR and fibrinogen for the prediction of disease-free survival (DFS) were 2.39 and $3.21 \mathrm{~g} / 1$, with areas under the curve (AUCs) of 0.778 (95\% CI, 0.730-0.827) and 0.584 (95\% CI, 0.522-0.646), respectively (Fig. 1A). The optimal cut-off values of NLR and fibrinogen for the prediction of overall survival (OS) were 2.20 and $3.21 \mathrm{~g} / 1$, with AUCs of 0.829 (95\% CI, 0.792-0.866) and 0.582 (95\% CI, 0.506-0.658), respectively (Fig. 1B). In terms of the highest Youden index, the optimal cut-off values of NLR and fibrinogen were 2.20 and $3.21 \mathrm{~g} / \mathrm{l}$, respectively. The sensitivity and specificity of NLR for the prediction of DFS were 83.8 and $61.7 \%$, and for the prediction of OS were 95.4 and $60.8 \%$, respectively. The sensitivity and specificity of fibrinogen for the prediction of DFS were 41.4 and $78.6 \%$, whereas those for the prediction of OS were 41.5 and $77.8 \%$, respectively. Based on the cut-off values for NLR and fibrinogen, the cohort was divided into three groups which were assigned different F-NLR scores as follows: Score 2, fibrinogen $>3.21 \mathrm{~g} / 1$ and NLR $>2.20$; score 1, fibrinogen $>3.21 \mathrm{~g} / 1$ or NLR $>2.20$; and score 0 , fibrinogen $\leq 3.21 \mathrm{~g} / 1$ and NLR $\leq 2.20$.

Statistical analysis. A two-tailed $\chi^{2}$ test was used to evaluate the associations between F-NLR and clinicopathological characteristics. DFS and OS were calculated using the Kaplan-Meier method, and differences in survival rates among the groups were compared by log-rank tests. Prognostic factors were analyzed using the Cox proportional hazards model. The hazard ratio was estimated with $95 \% \mathrm{CI}$. SPSS version 19.0 (IBM Corp.) was used for data analysis. $\mathrm{P}<0.05$ (two-sided) was considered to indicate a statistically significant difference.

\section{Results}

Clinicopathological characteristics of patients with BC. As shown in Table I, a total of 906 patients were enrolled in the present study. The mean age of the patients was $50 \pm 12$ years (range, 22-80 years). There were 494 (54.5\%) patients aged 
A

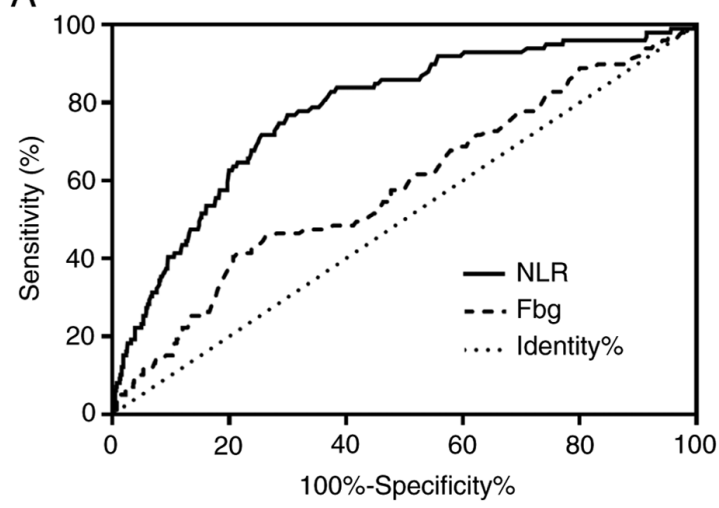

B

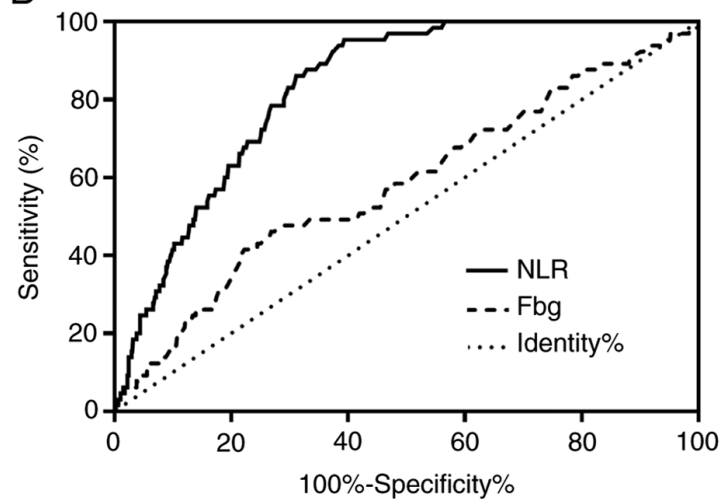

Figure 1. (A) ROC curves of NLR and plasma fibrinogen levels for the prediction of the disease-free survival of patients with resectable breast cancer. NLR: AUC, 0.778; 95\% CI, 0.730-0.827; P<0.001. Fibrinogen: AUC, 0.584; 95\% CI, 0.522-0.646; P=0.007. (B) ROC curves of NLR and plasma fibrinogen levels for the prediction of the overall survival of patients with resectable breast cancer. NLR: AUC, 0.829; 95\% CI, 0.792-0.866; P<0.001. Fibrinogen: AUC, 0.582; 95\% CI, 0.506-0.658; P=0.027. AUC, area under the curve; Fbg, fibrinogen; NLR, neutrophil-to-lymphocyte ratio; ROC, receiver operating characteristic.

$\leq 50$ years, and $491(54.2 \%)$ patients with T1 stage tumors. There were 385 (42.5\%) patients with lymph node positivity, including $163(18.0 \%)$ patients with $\mathrm{N} 2$ and N3 stage tumors. According to the AJCC guidelines, 362 (40.0\%) patients had stage II BC, whereas 168 (18.5\%) patients had stage III BC. Most patients $(700 ; 77.3 \%)$ had a positive hormone receptor status, and 249 (27.5\%) patients were HER2 positive. Based on the F-NLR scoring system, the whole cohort was divided into three groups as follows: Score 0, 444 (49.0\%) patients; score 1, $291(32.1 \%)$ patients; and score 2, $171(18.9 \%)$ patients. The median and mean follow-up times of survivors were 57 months (range, 5-83 months) and 53.9 months, respectively. The 5-year DFS and OS rates for the entire cohort were 89.0 and $92.2 \%$, respectively.

Association between F-NLR score and clinicopathological characteristics. As shown in Table II, age $(\mathrm{P}<0.001)$, tumor size $(\mathrm{P}=0.001)$, nodal positivity $(\mathrm{P}=0.029)$, TNM stage $(\mathrm{P}=0.002)$ and lymphovascular invasion $(\mathrm{P}<0.001)$ were significantly different among the three F-NLR score groups.

Univariate and multivariate analyses for DFS. The univariate analysis demonstrated that tumor size $(\mathrm{P}<0.001)$, nodal positivity $(\mathrm{P}<0.001)$, TNM stage $(\mathrm{P}<0.001)$, hormone receptor status $(\mathrm{P}=0.015)$, HER2 status $(\mathrm{P}=0.005), \mathrm{Ki}-67$ index $(\mathrm{P}=0.039)$, lymphovascular invasion $(\mathrm{P}<0.001)$, histologic grade $(\mathrm{P}=0.018)$ and $\mathrm{F}-\mathrm{NLR}$ score $(\mathrm{P}<0.001)$ were significantly associated with DFS (Table III). Multivariate analysis demonstrated that F-NLR score $(\mathrm{P}<0.001)$, as well as TNM stage $(\mathrm{P}=0.005)$ and lymphovascular invasion $(\mathrm{P}=0.001)$, could independently predict DFS (Table III).

Univariate and multivariate analyses for OS. The univariate analysis revealed that tumor size $(\mathrm{P}<0.001)$, nodal positivity $(\mathrm{P}<0.001)$, TNM stage $(\mathrm{P}<0.001)$, hormone receptor status $(\mathrm{P}=0.013)$, HER2 status $(\mathrm{P}=0.001), \mathrm{Ki}-67$ index $(\mathrm{P}=0.007)$, lymphovascular invasion $(\mathrm{P}<0.001)$ and F-NLR score $(\mathrm{P}<0.001)$ were significantly associated with OS (Table IV). Multivariate analysis demonstrated that F-NLR score $(\mathrm{P}<0.001)$, as well as TNM stage $(\mathrm{P}=0.040)$ and lymphovascular invasion $(\mathrm{P}<0.001)$, could independently predict OS (Table IV).
Survival analysis of F-NLR score groups. Kaplan-Meier analyses and log-rank tests were used to compare differences in survival among patients in the three F-NLR score groups. The overall 5-year DFS and OS rates were 89.0 and $92.2 \%$, respectively. The 5-year DFS rate in the group with an F-NLR score of 2 was significantly lower than that in the groups with a score of 1 or 0 (74.0 vs. 87.5 or $95.7 \%$, respectively; $\mathrm{P}<0.001$; Fig. 2A). The 5-year OS rate in the group with an F-NLR score of 2 was significantly lower than that in the groups with a score of 1 or 0 (79.9 vs. 90.9 or $97.8 \%$, respectively; $\mathrm{P}<0.001$; Fig. 2B). Comparisons were also made in the 5-year DFS and OS rates between two groups based on only low/high NLR or low/high fibrinogen according to their cut-off values, and among the three groups based on F-NLR scores (Table SI). The results showed that the 5-year DFS rate in the group with an F-NLR score of $2(74.0 \%)$ was lower than that in the NLR-high $(78.7 \%)$ or fibrinogen-high groups $(80.6 \%)$. The 5-year OS rate in the group with an F-NLR score of 2 (79.9\%) was also lower than that in the NLR-high $(83.1 \%)$ or fibrinogen-high groups $(86.0 \%)$.

Further subgroup analysis revealed that the prognostic effect of the preoperative F-NLR score for patients with BC differed among TNM stages and molecular subtypes. When patients were stratified according to TNM stage, the F-NLR score retained a prognostic effect for the 5-year DFS in stages I ( $\mathrm{P}=0.006$; Fig. 3A), II $(\mathrm{P}<0.001$; Fig. 3C) and III $(\mathrm{P}<0.001$; Fig. 3E), as well as for the 5-year OS in stages I $(\mathrm{P}=0.011$; Fig. 3B), II ( $\mathrm{P}<0.001$; Fig. 3D) and III $(\mathrm{P}=0.004$; Fig. 3F). When the F-NLR score and TNM stage were stratified, the 5-year DFS ranged between 98.1\% (F-NLR 0, TNM I; Table V) and 52.3\% (F-NLR 2, TNM III; Table V), and the 5-year OS ranged between $100.0 \%$ (F-NLR 0, TNM I; Table V) and 65.4\% (F-NLR 2, TNM III; Table V). When patients were stratified on the basis of the molecular subtype of BC, the prognostic effect of F-NLR was notable for DFS and OS in the luminal B-like subtype (both $\mathrm{P}<0.001$; Fig. 4C and D) and the triple-negative subtype (DFS, $\mathrm{P}=0.029$; $\mathrm{OS}, \mathrm{P}=0.003$; Fig. $4 \mathrm{G}$ and $\mathrm{H}$ ). However, no differences in prognostic effect were observed in the luminal A-like (DFS, $\mathrm{P}=0.053$; OS, $\mathrm{P}=0.089$; Fig. $4 \mathrm{~A}$ and $\mathrm{B}$ ) and HER2 subtypes (DFS, $\mathrm{P}=0.076$; OS, $\mathrm{P}=0.440$; Fig. $4 \mathrm{E}$ and $\mathrm{F}$ ). 
Table I. Clinical baseline characteristics of the patients with resectable breast cancer.

\begin{tabular}{|c|c|}
\hline Characteristic & Value \\
\hline Age, years $($ mean $\pm S D)$ & $50 \pm 12$ \\
\hline \multicolumn{2}{|l|}{ Age, $\mathrm{n}(\%)$} \\
\hline$>50$ years & $412(45.5)$ \\
\hline$\leq 50$ years & $494(54.5)$ \\
\hline \multicolumn{2}{|l|}{ Tumor stage, n (\%) } \\
\hline $\mathrm{T} 1$ & $491(54.2)$ \\
\hline $\mathrm{T} 2$ & $344(38.0)$ \\
\hline $\mathrm{T} 3$ & $56(6.2)$ \\
\hline $\mathrm{T} 4$ & $15(1.6)$ \\
\hline \multicolumn{2}{|l|}{$\mathrm{N}$ stage, n $(\%)$} \\
\hline No & $521(57.5)$ \\
\hline N1 & $222(24.5)$ \\
\hline $\mathrm{N} 2$ & $89(9.8)$ \\
\hline N3 & $74(8.2)$ \\
\hline \multicolumn{2}{|l|}{ TNM stage, n (\%) } \\
\hline I & $376(41.5)$ \\
\hline II & $362(40.0)$ \\
\hline III & $168(18.5)$ \\
\hline \multicolumn{2}{|l|}{ Hormone receptor, $\mathrm{n}(\%)$} \\
\hline Positive & $700(77.3)$ \\
\hline Negative & $206(22.7)$ \\
\hline \multicolumn{2}{|l|}{ Estrogen receptor, n (\%) } \\
\hline Positive & $692(76.4)$ \\
\hline Negative & $214(23.6)$ \\
\hline \multicolumn{2}{|c|}{ Progesterone receptor, n (\%) } \\
\hline Positive & $622(68.7)$ \\
\hline Negative & $284(31.3)$ \\
\hline \multicolumn{2}{|l|}{ HER2, n (\%) } \\
\hline Positive & $249(27.5)$ \\
\hline Negative & $657(72.5)$ \\
\hline \multicolumn{2}{|l|}{ Histologic grade, $\mathrm{n}(\%)$} \\
\hline 1 & $129(14.2)$ \\
\hline 2 & $540(59.6)$ \\
\hline 3 & $237(26.2)$ \\
\hline \multicolumn{2}{|l|}{$\mathrm{Ki}-67, \mathrm{n}(\%)$} \\
\hline$>14 \%$ & $528(58.3)$ \\
\hline$\leq 14 \%$ & $378(41.7)$ \\
\hline \multicolumn{2}{|c|}{ Lymphovascular invasion, n (\%) } \\
\hline Positive & $184(20.3)$ \\
\hline Negative & $722(79.7)$ \\
\hline \multicolumn{2}{|l|}{ F-NLR score, n (\%) } \\
\hline 0 & $444(49.0)$ \\
\hline 1 & $291(32.1)$ \\
\hline 2 & $171(18.9)$ \\
\hline
\end{tabular}

HER2, human epidermal growth factor receptor 2; F-NLR, combination of fibrinogen concentration and neutrophil-to-lymphocyte ratio.

\section{Discussion}

Previous studies have demonstrated that elevated fibrinogen level, NLR and a high F-NLR score are associated with tumor development and shorter survival in esophageal squamous cell carcinoma $(26,29)$, non-small cell lung cancer (NSCLC) $(27,33)$ and gastric cancer $(28,34)$. Based on these findings, the present study investigated the effect of F-NLR on the prognosis of 906 patients with resectable $\mathrm{BC}$.

Inflammation is considered to be a hallmark of cancer (7). Cancer-associated inflammation can be both local and systemic. Local inflammation is mainly associated with the immune reaction in the tumor microenvironment, whereas systemic inflammation causes paraneoplastic symptoms through inflammatory mediators, such as cytokines in the systemic circulation (35). Solid tumors have the ability to raise immune cells and upregulate inflammatory cytokines, which then influence tumor angiogenesis, development and distant metastasis $(8,36)$. The inflammatory mediator colony stimulating factor 1 has been demonstrated to accelerate tumor cell proliferation and promote tumor metastasis via the recruitment of macrophages to pre-malignant areas (37). The oncogenic Ras is considered to upregulate the expression of the pro-inflammatory cytokine interleukin (IL)-8, leading to increased tumor volume and angiogenesis in nude mouse models (38). Cancer-associated cytokines promote the recruitment of myeloid cells to tumors that secrete IL-6 to boost the transformation and tumorigenesis of BC cells (39). Myeloid-derived suppressor cells (MDSCs), which are generated by cancer-associated myelopoiesis, may persist in the circulation (40). The concentration of circulating MDSCs is higher in patients with malignant tumors than in healthy individuals and is associated with advanced disease and distant metastasis $(41,42)$. The classic 'Th-17-like' inflammatory response to damaged epithelial junctions in tumor cells exacerbates tumor growth and progression (43). IL-22 and IL-32 are important agents in the 'Th-17 like' inflammatory response and have recently been demonstrated to be closely associated with tumor angiogenesis $(44,45)$. Collectively, these findings reveal a complex relationship between cancer-associated inflammation, tumorigenesis and tumor progression, which are mutually causal and reinforcing. In the process of cancer-mediated myelopoiesis, the number of circulating granulocytes is increased, with neutrophils being most abundant (41). Furthermore, a study demonstrated that neutrophils may be used as an independent prognostic indicator for malignant tumors (46). Additionally, other studies have demonstrated the prognostic utility of NLR in various types of cancer (17-20).

A hypercoagulable state is much more likely to occur in patients with cancer compared with healthy individuals and has been associated with malignancy (47). Fibrinogen is frequently deposited in the stroma of solid tumors (48). The expression of fibrinogen can be upregulated by the inflammatory cytokine IL-6 (49). The fibrinogen synthesized and secreted by BC epithelial cells has been demonstrated to mediate cell proliferation and form an extracellular matrix that binds to tumor cell surfaces (50-52). This process forms a solid framework around the cancer cells, which may increase their adhesion, invasion and metastasis. Previous studies $(14,22)$ have reported that fibrinogen promotes spontaneous metastasis, possibly by limiting the elimination of new micrometastases by natural killer cells. Furthermore, hyperfibrinogenemia has been 
Table II. Association between F-NLR scores and clinicopathological factors in patients with resectable breast cancer.

\begin{tabular}{|c|c|c|c|c|c|}
\hline \multirow[b]{2}{*}{ Variables } & \multirow[b]{2}{*}{ All, $\mathrm{n}$} & \multicolumn{3}{|c|}{ F-NLR score, $\mathrm{n}$} & \multirow[b]{2}{*}{ P-value } \\
\hline & & 0 & 1 & 2 & \\
\hline Age, years & & & & & $<0.001$ \\
\hline$>50$ & 412 & 180 & 131 & 101 & \\
\hline$\leq 50$ & 494 & 264 & 160 & 70 & \\
\hline Tumor size, $\mathrm{cm}$ & & & & & 0.001 \\
\hline$>2$ & 415 & 180 & 137 & 98 & \\
\hline$\leq 2$ & 491 & 264 & 154 & 73 & \\
\hline Nodal positivity & & & & & 0.029 \\
\hline Negative & 521 & 267 & 171 & 83 & \\
\hline Positive & 385 & 177 & 120 & 88 & \\
\hline TNM stage & & & & & 0.002 \\
\hline I & 376 & 209 & 114 & 53 & \\
\hline II & 362 & 169 & 119 & 74 & \\
\hline III & 168 & 66 & 58 & 44 & \\
\hline Hormone receptor & & & & & 0.270 \\
\hline Positive & 700 & 353 & 217 & 130 & \\
\hline Negative & 206 & 91 & 74 & 41 & \\
\hline HER2 & & & & & 0.760 \\
\hline Positive & 249 & 123 & 76 & 50 & \\
\hline Negative & 657 & 321 & 215 & 121 & \\
\hline $\mathrm{Ki}-67, \%$ & & & & & 0.226 \\
\hline$>14$ & 528 & 246 & 177 & 105 & \\
\hline$\leq 14$ & 378 & 198 & 114 & 66 & \\
\hline Lymphovascular invasion & & & & & $<0.001$ \\
\hline Positive & 184 & 64 & 67 & 53 & \\
\hline Negative & 722 & 380 & 224 & 118 & \\
\hline Histologic grade & & & & & 0.070 \\
\hline 1 & 129 & 68 & 32 & 29 & \\
\hline 2 & 540 & 271 & 167 & 102 & \\
\hline 3 & 237 & 105 & 92 & 40 & \\
\hline Molecular subtype & & & & & 0.640 \\
\hline Luminal A-like & 291 & 152 & 90 & 49 & \\
\hline Luminal B-like & 409 & 201 & 127 & 81 & \\
\hline HER2 & 96 & 45 & 33 & 18 & \\
\hline Triple-negative & 110 & 46 & 41 & 23 & \\
\hline
\end{tabular}

F-NLR, combination of fibrinogen concentration and neutrophil-to-lymphocyte ratio; HER2, human epidermal growth factor receptor 2.

demonstrated to be associated with poor outcomes in various types of cancer (23-25).

The present study revealed a strong association between high F-NLR score and larger tumor size, nodal positivity, late TNM stage and lymphovascular invasion for resectable BC. These findings are consistent with the results of previous studies on gastric cancer $(28)$ and NSCLC $(27,33)$. Notably, the F-NLR score was identified as an independent predictor for DFS and OS in the present study, which is consistent with previous studies on various types of cancer (26-29,33-34). This suggests that the F-NLR score could be used to classify the survival risks of patients. Although the ROC curves indicate that NLR has a much higher predictive efficiency than fibrinogen for DFS and OS in patients with resectable $\mathrm{BC}$, the effect of fibrinogen on prognosis merits consideration, despite its relatively low prediction efficiency. On the basis of survival analyses, the present study found that the combination of NLR and fibrinogen classified the whole cohort more distinctly and helped to screen out the subgroup with the worst prognosis, which comprised those patients in which NLR and fibrinogen were both high (F-NLR score 2). Greater attention should be focused on those patients, to ensure that adequate adjuvant therapy and close follow-up are applied. In the subgroup analysis of TNM stage in the present study, the F-NLR score continued to exhibit an important prognostic effect, which is similar to previous findings in gastric cancer (28). The prognosis of patients in each 
Table III. Univariate and multivariate analysis of clinical characteristics in relation to disease-free survival.

\begin{tabular}{|c|c|c|c|c|c|c|c|}
\hline \multirow[b]{2}{*}{ Variable } & \multirow[b]{2}{*}{ Patients, $\mathrm{n}$} & \multicolumn{3}{|c|}{ Univariate analysis } & \multicolumn{3}{|c|}{ Multivariate analysis } \\
\hline & & HR & $95 \% \mathrm{CI}$ & P-value & HR & $95 \% \mathrm{CI}$ & P-value \\
\hline Age, years $(\leq 50 />50)$ & $494 / 412$ & 0.886 & $0.595-1.320$ & 0.552 & & & \\
\hline Tumor size, $\mathrm{cm}(\leq 2 />2)$ & $491 / 415$ & 2.602 & $1.707-3.965$ & $<0.001$ & 1.104 & $0.686-1.776$ & 0.684 \\
\hline Nodal positivity (negative/positive) & $521 / 385$ & 3.371 & $2.195-5.175$ & $<0.001$ & 1.284 & $0.686-2.404$ & 0.434 \\
\hline TNM stage (I/II/III) & $376 / 362 / 168$ & 2.669 & $2.032-3.506$ & $<0.001$ & 1.889 & $1.213-2.943$ & 0.005 \\
\hline Hormone receptor (positive/negative) & $700 / 206$ & 1.683 & $1.105-2.565$ & 0.015 & 1.251 & $0.797-1.963$ & 0.331 \\
\hline HER2 (negative/positive) & $657 / 249$ & 1.786 & $1.194-2.673$ & 0.005 & 1.395 & $0.921-2.112$ & 0.116 \\
\hline $\mathrm{Ki}-67, \%(\leq 14 />14)$ & $378 / 528$ & 1.560 & $1.024-2.377$ & 0.039 & 1.082 & $0.694-1.687$ & 0.726 \\
\hline $\begin{array}{l}\text { Lymphovascular invasion } \\
\text { (negative/positive) }\end{array}$ & $722 / 184$ & 3.201 & $2.148-4.769$ & $<0.001$ & 2.034 & $1.350-3.065$ & 0.001 \\
\hline Histologic grade (1/2/3) & $129 / 540 / 237$ & 1.473 & $1.068-2.030$ & 0.018 & 1.193 & $0.839-1.696$ & 0.325 \\
\hline F-NLR score $(0 / 1 / 2)$ & $444 / 291 / 171$ & 2.584 & $2.004-3.332$ & $<0.001$ & 2.279 & $1.758-2.954$ & $<0.001$ \\
\hline
\end{tabular}

HR, hazard ratio; HER2, human epidermal growth factor receptor 2; F-NLR, combination of fibrinogen concentration and neutrophil-tolymphocyte ratio.

Table IV. Univariate and multivariate analysis of clinical characteristics in relation to overall survival.

\begin{tabular}{|c|c|c|c|c|c|c|c|}
\hline \multirow[b]{2}{*}{ Variable } & \multirow[b]{2}{*}{ Patients, $\mathrm{n}$} & \multicolumn{3}{|c|}{ Univariate analysis } & \multicolumn{3}{|c|}{ Multivariate analysis } \\
\hline & & HR & $95 \% \mathrm{CI}$ & P-value & HR & $95 \% \mathrm{CI}$ & P-value \\
\hline Age, years $(\leq 50 />50)$ & $494 / 412$ & 0.660 & $0.397-1.098$ & 0.110 & & & \\
\hline Tumor size, $\mathrm{cm}(\leq 2 />2)$ & $491 / 415$ & 2.957 & $1.732-5.046$ & $<0.001$ & 1.213 & $0.680-2.163$ & 0.513 \\
\hline $\begin{array}{l}\text { Nodal positivity } \\
\text { (negative/positive) }\end{array}$ & $521 / 385$ & 4.801 & $2.696-8.549$ & $<0.001$ & 1.720 & $0.771-3.838$ & 0.185 \\
\hline TNM stage (I/II/III) & $376 / 362 / 1688$ & 3.181 & $2.242-4.514$ & $<0.001$ & 1.748 & $1.025-2.983$ & 0.040 \\
\hline $\begin{array}{l}\text { Hormone receptor } \\
\text { (positive/negative) }\end{array}$ & $700 / 206$ & 1.902 & $1.144-3.162$ & 0.013 & 1.439 & $0.857-2.417$ & 0.168 \\
\hline HER2 (negative/positive) & $657 / 249$ & 2.226 & $1.365-3.631$ & 0.001 & 1.576 & $0.959-2.589$ & 0.073 \\
\hline $\mathrm{Ki}-67, \%(\leq 14 />14)$ & $378 / 528$ & 2.145 & $1.233-3.730$ & 0.007 & 1.604 & $0.916-2.809$ & 0.098 \\
\hline $\begin{array}{l}\text { Lymphovascular invasion } \\
\text { (negative/positive) }\end{array}$ & $722 / 184$ & 5.634 & $3.448-9.206$ & $<0.001$ & 3.406 & $2.058-5.637$ & $<0.001$ \\
\hline Histologic grade (1/2/3) & $129 / 540 / 237$ & 1.461 & $0.983-2.172$ & 0.060 & & & \\
\hline F-NLR score $(0 / 1 / 2)$ & $444 / 291 / 171$ & 2.916 & $2.109-4.032$ & $<0.001$ & 2.414 & $1.738-3.353$ & $<0.001$ \\
\hline
\end{tabular}

HR, hazard ratio; HER2, human epidermal growth factor receptor 2; F-NLR, combination of fibrinogen concentration and neutrophil-tolymphocyte ratio.

F-NLR group differed significantly according to disease stage. Furthermore, in the molecular subgroup analysis, the predictive significance of F-NLR was highest for the luminal B-like and triple-negative $\mathrm{BC}$ subtypes.

The present study demonstrated that the F-NLR score is a powerful prognostic index for patients with resectable BC. However, the results should be considered in the context of several limitations. First, the present study was a retrospective study conducted at a single center and the statistical capacity was limited by the small sample size. Second, the follow-up was of short duration. Third, hematological indicators fluctuate under the influence of the internal environment, which means the results of a single blood test may not adequately reflect the condition of an individual.

In conclusion, the preoperative F-NLR score was a strong and independent unfavorable index of survival in patients with resectable $\mathrm{BC}$, which may be of great significance for the identification of high-risk patients and provision of accurate treatment. Furthermore, as a marker, the F-NLR score is simple and inexpensive to analyze, suggesting that it is potentially applicable to clinical practice. However, further research should be conducted to confirm this. 
A

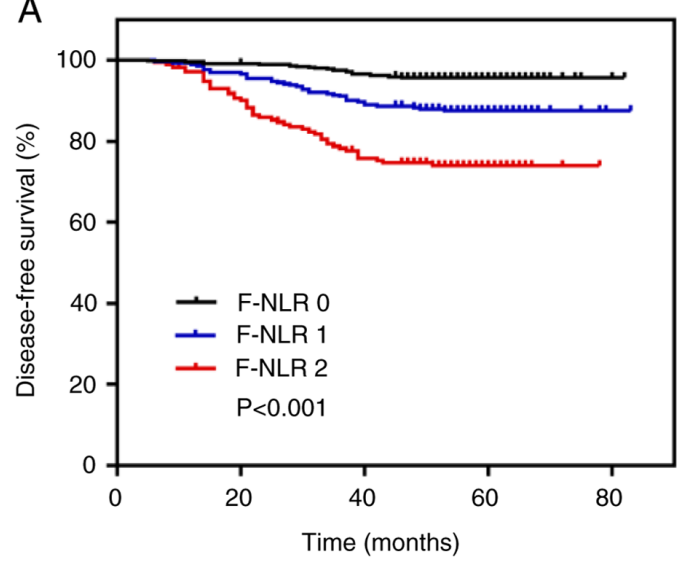

B

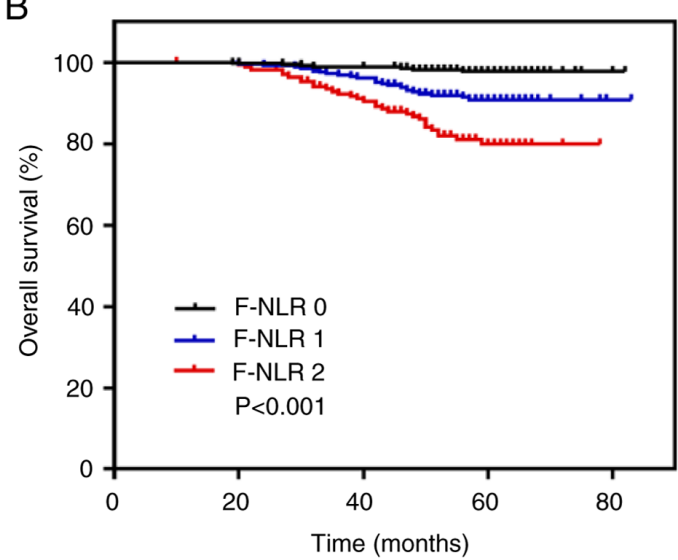

Figure 2. Survival curves of patients with resectable breast cancer based on an F-NLR score of 0, 1 or 2. (A) Disease-free survival and (B) overall survival curves (log-rank test). F-NLR, combination of fibrinogen concentration and neutrophil-to-lymphocyte ratio.

A

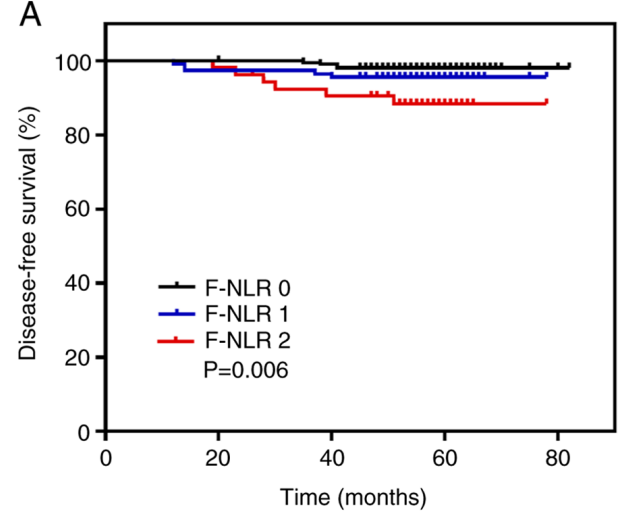

C

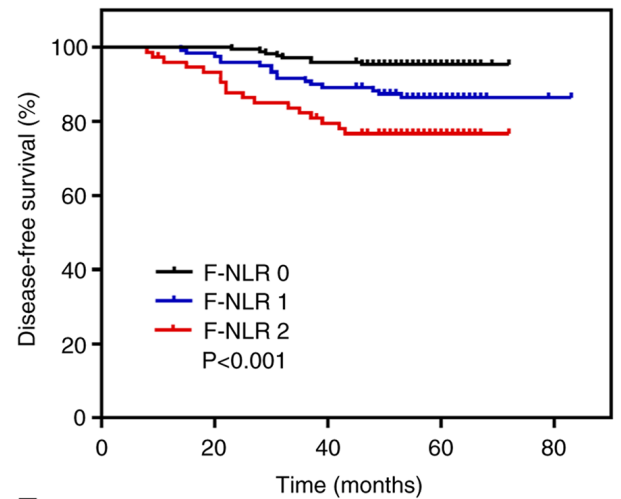

E

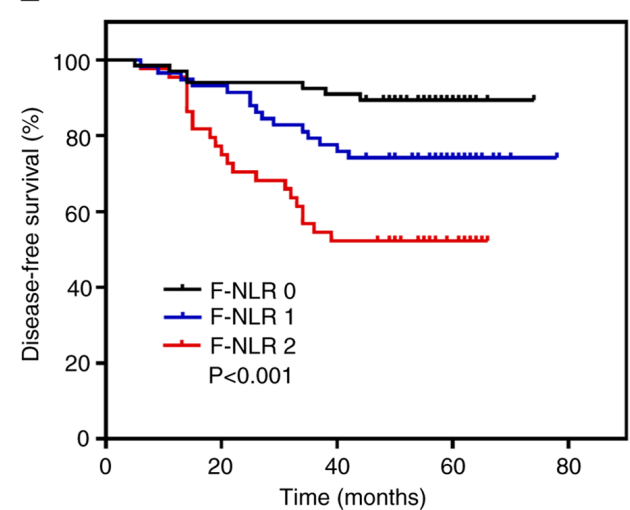

B

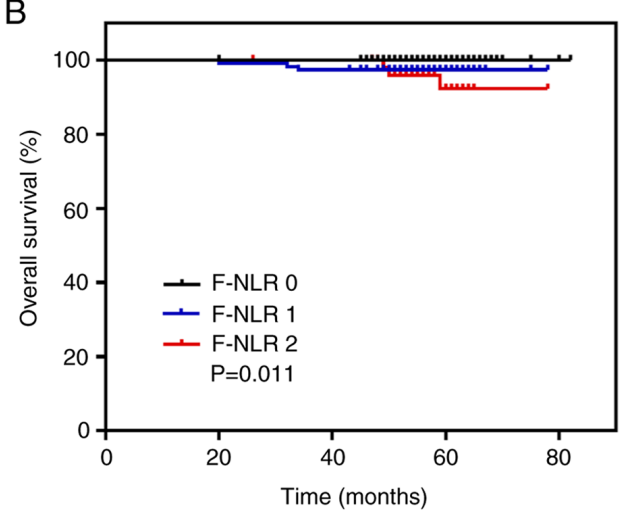

D

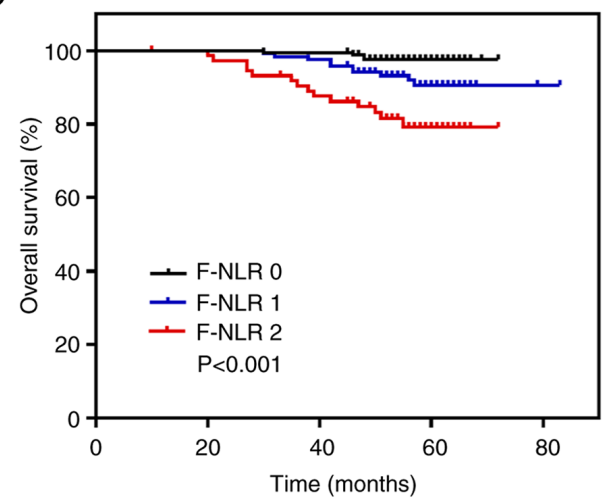

F

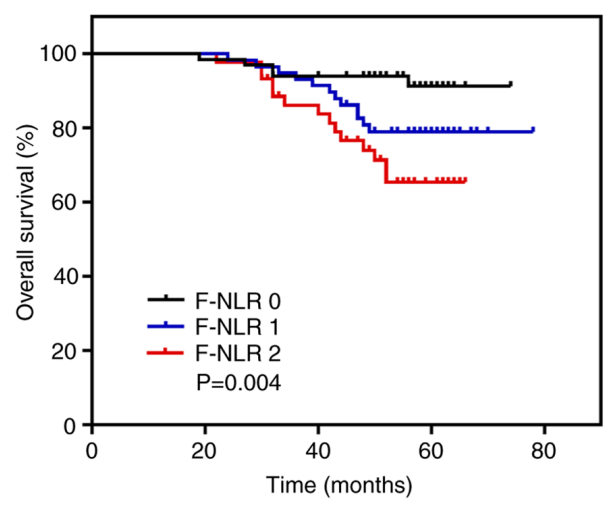

Figure 3. Survival curves of patients with resectable BC (stages I-III) based on an F-NLR score or 0, 1 or 2. (A) DFS and (B) OS curves of patients with stage I BC. (C) DFS and (D) OS curves of patients with stage II BC. (E) DFS and (F) OS curves of patients with stage III BC (all log-rank test). BC, breast cancer; DFS, disease-free survival; F-NLR, combination of fibrinogen concentration and neutrophil-to-lymphocyte ratio; OS, overall survival. 
Table V. Association between F-NLR score and 5-year DFS or OS in patients with resectable breast cancer of stages I, II and III.

\begin{tabular}{|c|c|c|c|c|c|c|c|c|}
\hline \multirow[b]{2}{*}{ F-NLR } & \multicolumn{4}{|c|}{ 5-year DFS rate $(\%)$} & \multicolumn{4}{|c|}{5 -year OS rate $(\%)$} \\
\hline & I & II & III & All & I & II & III & All \\
\hline 0 & 98.1 & 95.3 & 89.4 & 95.7 & 100 & 97.6 & 91.3 & 97.8 \\
\hline 1 & 95.6 & 86.4 & 74.1 & 87.5 & 97.4 & 90.6 & 79.0 & 90.9 \\
\hline 2 & 88.4 & 76.7 & 52.3 & 74.0 & 92.2 & 79.2 & 65.4 & 79.9 \\
\hline $\mathrm{P}$-value & 0.006 & $<0.001$ & $<0.001$ & $<0.001$ & 0.011 & $<0.001$ & 0.004 & $<0.001$ \\
\hline
\end{tabular}

F-NLR, combination of fibrinogen concentration and neutrophil-to-lymphocyte ratio; DFS, disease-free survival; OS, overall survival.

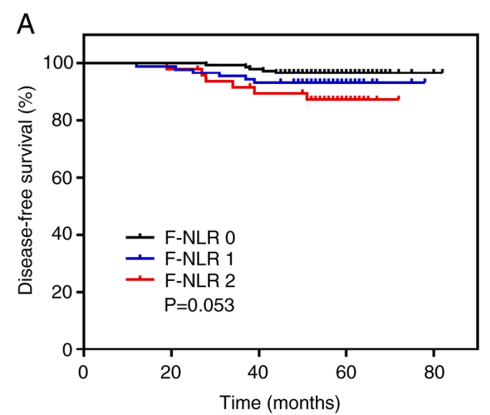

C

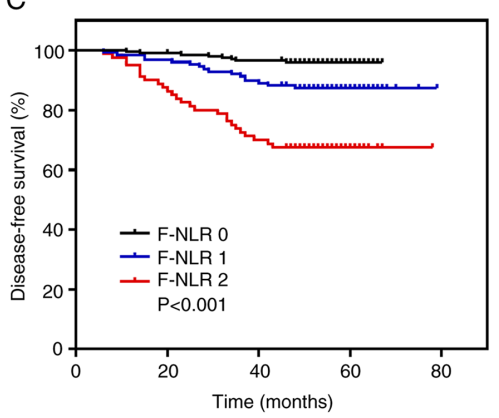

E

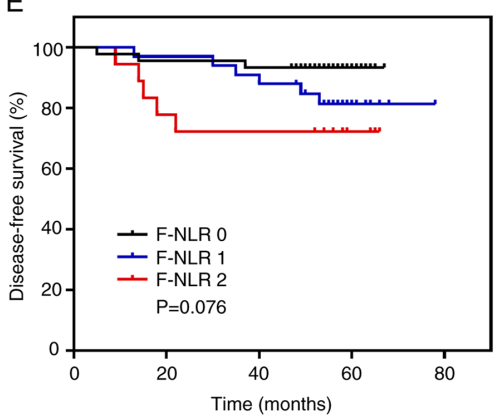

G

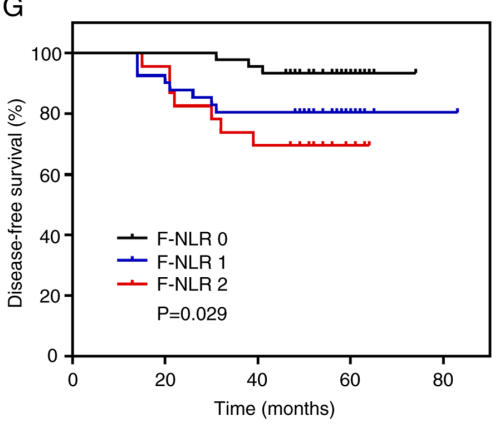

B

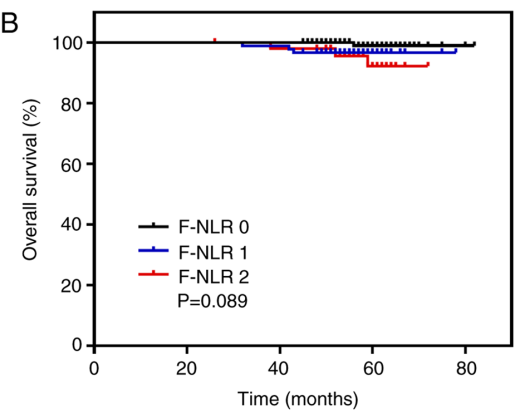

D

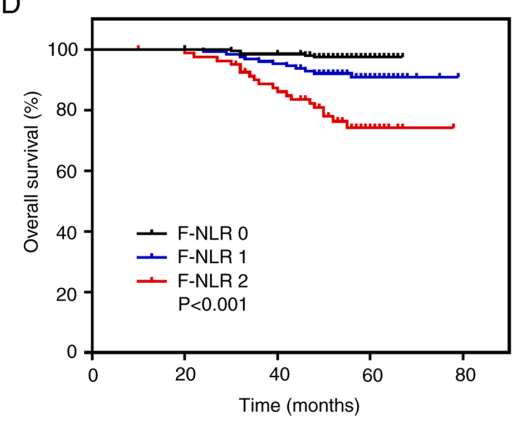

$\mathrm{F}$

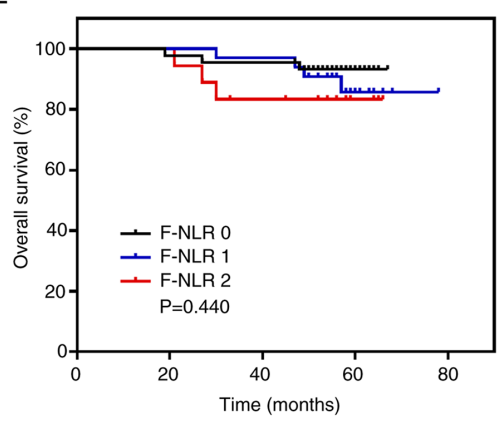

$\mathrm{H}$

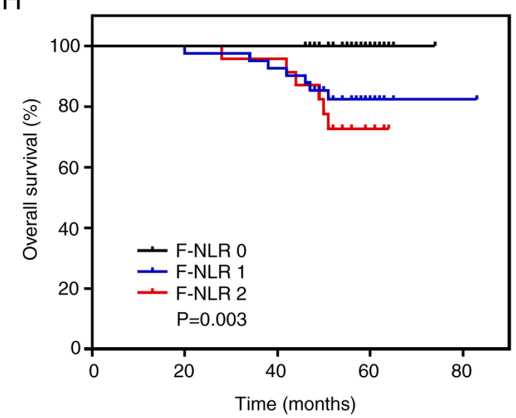

Figure 4. Survival curves of patients with resectable BC with different molecular subtypes and F-NLR scores of 0,1 and 2. (A) DFS and (B) OS curves of patients with luminal A-like subtype BC. (C) DFS and (D) OS curves of patients with luminal B-like subtype BC. (E) DFS and (F) OS curves of patients with HER2 subtype BC. (G) DFS and (H) OS curves of patients with triple-negative subtype BC (all log-rank test). BC, breast cancer; DFS, disease-free survival; F-NLR, combination of fibrinogen concentration and neutrophil-to-lymphocyte ratio; HER2, human epidermal growth factor receptor 2; OS, overall survival. 


\section{Acknowledgements}

Not applicable.

\section{Funding}

This study was supported by Fundamental Research Funds for the Central Universities (grant no. 3332020001).

\section{Availability of data and materials}

The datasets used and/or analyzed during the current study are available from the corresponding author on reasonable request.

\section{Authors' contributions}

$\mathrm{XC}$ designed the present study, carried out the experiments, collected and analyzed the data, and wrote the manuscript. YZ, FM and YL assisted with data collection and analysis, and also modified and revised the manuscript. QS conceived the present study and was involved in drafting the manuscript, coordinating the whole research process, and revising and finalizing the manuscript. All authors read and approved the final manuscript.

\section{Ethics approval and consent to participate}

The present study was approved by Ethical Committee/ Institutional Review Board of Peking Union Medical College Hospital. Due to the retrospective nature of the present study, formal consent was not required.

\section{Patient consent for publication}

Not applicable.

\section{Competing interests}

The authors declare that they have no competing interests.

\section{References}

1. Bray F, Ferlay J, Soerjomataram I, Siegel RL, Torre LA and Jemal A: Global cancer statistics 2018: GLOBOCAN estimates of incidence and mortality worldwide for 36 cancers in 185 countries. CA Cancer J Clin 68: 394-424, 2018.

2. Chen W, Zheng R, Baade PD, Zhang S, Zeng H, Bray F, Jemal A, Yu XQ and He J: Cancer statistics in China, 2015. CA Cancer J Clin 66: 115-132, 2016

3. Goss PE, Strasser-Weippl K, Lee-Bychkovsky BL, Fan L, Li J, Chavarri-Guerra Y, Liedke PER, Pramesh CS Badovinac-Crnjevic T, Sheikine Y, et al: Challenges to effective cancer control in China, India, and Russia. Lancet Oncol 15 489-538, 2014

4. Varghese $\mathrm{C}$ and Shin HR: Strengthening cancer control in China. Lancet Oncol 15: 484-485, 2014

5. Li L, Ji J, Wang JB, Niyazi M, Qiao YL and Boffetta P: Attributable causes of breast cancer and ovarian cancer in China: Reproductive factors, oral contraceptives and hormone replacement therapy. Chin J Cancer Res 24: 9-17, 2012.

6. Virchow R: An address on the value of pathological experiments. Br Med J 2: 198-203, 1881.

7. Hanahan D and Weinberg RA: Hallmarks of cancer: The next generation. Cell 144: 646-674, 2011.

8. Grivennikov SI, Greten FR and Karin M: Immunity, inflammation, and cancer. Cell 140: 883-899, 2010.
9. Balkwill $\mathrm{F}$ and Mantovani A: Inflammation and cancer: Back to Virchow? Lancet 357: 539-545, 2001.

10. Mantovani A, Allavena P, Sica A and Balkwill F: Cancer-related inflammation. Nature 454: 436-444, 2008.

11. Shrotriya S, Walsh D, Bennani-Baiti N, Thomas S and Lorton C: $\mathrm{C}$-reactive protein is an important biomarker for prognosis tumor recurrence and treatment response in adult solid tumors: A systematic review. PLoS One 10: e0143080, 2015.

12. Sengupta S, Lohse CM, Cheville JC, Leibovich BC, Thompson RH, Webster WS, Frank I, Zincke H, Blute ML and Kwon ED: The preoperative erythrocyte sedimentation rate is an independent prognostic factor in renal cell carcinoma. Cancer 106: 304-312, 2006.

13. Uribe-Querol E and Rosales C: Neutrophils in cancer: Two sides of the same coin. J Immunol Res 2015: 983698, 2015.

14. Palumbo JS, Kombrinck KW, Drew AF, Grimes TS, Kiser JH, Degen JL and Bugge TH: Fibrinogen is an important determinant of the metastatic potential of circulating tumor cells. Blood 96: 3302-3309, 2000

15. McNamara MG, Templeton AJ, Maganti M, Walter T, Horgan AM, McKeever L, Min T, Amir E and Knox JJ: Neutrophil/lymphocyte ratio as a prognostic factor in biliary tract cancer. Eur J Cancer 50: 1581-1589, 2014

16. McMillan DC, Crozier JE, Canna K, Angerson WJ and McArdle CS: Evaluation of an inflammation-based prognostic score (GPS) in patients undergoing resection for colon and rectal cancer. Int J Colorectal Dis 22: 881-886, 2007.

17. Mano Y, Shirabe K, Yamashita Y, Harimoto N, Tsujita E, Takeishi K, Aishima S, Ikegami T, Yoshizumi T, Yamanaka T and Maehara Y: Preoperative neutrophil-to-lymphocyte ratio is a predictor of survival after hepatectomy for hepatocellular carcinoma: A retrospective analysis. Ann Surg 258: 301-305, 2013.

18. Yodying H, Matsuda A, Miyashita M, Matsumoto S, Sakurazawa N, Yamada M and Uchida E: Prognostic significance of neutrophil-to-lymphocyte ratio and platelet-to-lymphocyte ratio in oncologic outcomes of esophageal cancer: A systematic review and meta-analysis. Ann Surg Oncol 23: 646-654, 2016.

19. Wariss BR, de Souza Abrahão K, de Aguiar SS, Bergmann A and Thuler LCS: Effectiveness of four inflammatory markers in predicting prognosis in 2374 women with breast cancer. Maturitas 101: 51-56, 2017.

20. Liu X, Qu JK, Zhang J, Yan Y, Zhao XX, Wang JZ, Qu HY, Liu L, Wang JS and Duan XY: Prognostic role of pretreatment neutrophil to lymphocyte ratio in breast cancer patients: A meta-analysis. Medicine (Baltimore) 96: e8101, 2017.

21. Satoh T, Matsumoto K, Tanaka YO, Akiyama A, Nakao S, Sakurai M, Ochi H, Onuki M, Minaguchi T, Sakurai $\mathrm{H}$ and Yoshikawa $\mathrm{H}$ : Incidence of venous thromboembolism before treatment in cervical cancer and the impact of management on venous thromboembolism after commencement of treatment Thromb Res 131: e127-e132, 2013.

22. Palumbo JS, Talmage KE, Massari JV, La Jeunesse CM, Flick MJ, Kombrinck KW, Jirousková $M$ and Degen JL: Platelets and fibrin(ogen) increase metastatic potential by impeding natural killer cell-mediated elimination of tumor cells. Blood 105: 178-185, 2005.

23. Zhao K, Deng H, Qin Y, Liao W and Liang W: Prognostic significance of pretreatment plasma fibrinogen and platelet levels in patients with early-stage cervical cancer. Gynecol Obstet Invest 79: 25-33, 2015 .

24. Jones JM, McGonigle NC, McAnespie M, Cran GW and Graham AN: Plasma fibrinogen and serum C-reactive protein are associated with non-small cell lung cancer. Lung Cancer 53: 97-101, 2006

25. Mei Y,Zhao S,LuX, Liu H,Li X and Ma R: Clinical and prognostic significance of preoperative plasma fibrinogen levels in patients with operable breast cancer. PLoS One 11: e0146233, 2016.

26. Kijima T, Arigami T, Uchikado Y, Uenosono Y, Kita Y, Owaki T, Mori S, Kurahara H, Kijima Y, Okumura H, et al: Combined fibrinogen and neutrophil-lymphocyte ratio as a prognostic marker of advanced esophageal squamous cell carcinoma. Cancer Sci 108: 193-199, 2017.

27. Huang W, Wang S, Zhang H, Zhang B and Wang C: Prognostic significance of combined fibrinogen concentration and neutrophil-to-lymphocyte ratio in patients with resectable non-small cell lung cancer. Cancer Biol Med 15: 88-96, 2018.

28. Liu X, Liu Z, Lin E, Chen Y, Sun X and Zhou Z: A cumulative score based on preoperative fibrinogen and the neutrophil-lymphocyte ratio to predict outcomes in resectable gastric cancer. Cancer Manag Res 10: 3007-3014, 2018. 
29. Arigami T, Okumura H, Matsumoto M, Uchikado Y, Uenosono Y, Kita Y, Owaki T, Mori S, Kurahara H, Kijima Y, et al: Analysis of the fibrinogen and neutrophil-lymphocyte ratio in esophageal squamous cell carcinoma: A promising blood marker of tumor progression and prognosis. Medicine (Baltimore) 94: e1702, 2015.

30. Edge SB, Byrd DR, Compton CC, Fritz AG, Greene FL and Trotti A: AJCC Cancer Staging Manual. 7th edition. Springer, New York, NY, 2010.

31. Wolff AC, Hammond ME, Hicks DG, Dowsett M, McShane LM, Allison KH, Allred DC, Bartlett JMS, Bilous M, Fitzgibbons $\mathrm{P}$, et al: Recommendations for human epidermal growth factor receptor 2 testing in breast cancer: American society of clinical oncology/college of American pathologists clinical practice guideline update. J Clin Oncol 31: 3997-4013, 2013.

32. National Comprehensive Cancer Network. The NCCN Breast Cancer Clinical Practice Guidelines in Oncology (version 1.2012) (EB/OL). Accessed from: https://www.nccn.org/professionals/physician_gls/default.aspx.

33. Wang H, Zhao J, Zhang M, Han L, Wang M and Xingde L: The combination of plasma fibrinogen and neutrophil lymphocyte ratio (F-NLR) is a predictive factor in patients with resectable non small cell lung cancer. J Cell Physiol 233: 4216-4224, 2018.

34. Arigami T, Uenosono Y, Matsushita D, Yanagita S, Uchikado Y Kita Y, Mori S, Kijima Y, Okumura H, Maemura K, et al: Combined fibrinogen concentration and neutrophil-lymphocyte ratio as a prognostic marker of gastric cancer. Oncol Lett 11 : $1537-1544,2016$

35. Diakos CI, Charles KA, McMillan DC and Clarke SJ: Cancer-related inflammation and treatment effectiveness. Lancet Oncol 15: e493-e503, 2014.

36. Coussens LM, Zitvogel L and Palucka AK: Neutralizing tumor-promoting chronic inflammation: A magic bullet? Science 339: 286-291, 2013.

37. Lin EY, Nguyen AV, Russell RG and Pollard JW: Colony-stimulating factor 1 promotes progression of mammary tumors to malignancy. J Exp Med 193: 727-740, 2001.

38. Sparmann A and Bar-Sagi D: Ras-induced interleukin-8 expression plays a critical role in tumor growth and angiogenesis. Cancer Cell 6: 447-458, 2004

39. Rokavec M, Wu W and Luo JL: IL6-mediated suppression of miR-200c directs constitutive activation of inflammatory signaling circuit driving transformation and tumorigenesis. Mol Cell 45: 777-789, 2012.

40. Gabrilovich DI, Ostrand-Rosenberg S and Bronte V: Coordinated regulation of myeloid cells by tumours. Nat Rev Immunol 12: 253-268, 2012
41. Ohki S, Shibata M, Gonda K, Machida T, Shimura T, Nakamura I, Ohtake T, Koyama Y, Suzuki S, Ohto H and Takenoshita S: Circulating myeloid-derived suppressor cells are increased and correlate to immune suppression, inflammation and hypoproteinemia in patients with cancer. Oncol Rep 28: 453-458, 2012.

42. Diaz-Montero CM, Salem ML, Nishimura MI, Garrett-Mayer E, Cole DJ and Montero AJ: Increased circulating myeloid-derived suppressor cells correlate with clinical cancer stage, metastatic tumor burden, and doxorubicin-cyclophosphamide chemotherapy. Cancer Immunol Immunother 58: 49-59, 2009.

43. Grivennikov SI, Wang K, Mucida D, Stewart CA, Schnabl B, Jauch D, Taniguchi K, Yu GY, Osterreicher CH, Hung KE, et al: Adenoma-linked barrier defects and microbial products drive IL-23/IL-17-mediated tumour growth. Nature 491: 254-258, 2012.

44. Protopsaltis NJ, Liang W, Nudleman E and Ferrara N: Interleukin-22 promotes tumor angiogenesis. Angiogenesis 22: 311-323, 2019.

45. Hong JT, Son DJ, Lee CK, Yoon DY, Lee DH and Park MH: Interleukin 32, inflammation and cancer. Pharmacol Ther 174: 127-137, 2017.

46. Guthrie GJ, Charles KA, Roxburgh CS, Horgan PG, McMillan DC and Clarke SJ: The systemic inflammation-based neutrophil-lymphocyte ratio: Experience in patients with cancer. Crit Rev Oncol Hematol 88: 218-230, 2013

47. Goldenberg N, Kahn SR and Solymoss S: Markers of coagulation and angiogenesis in cancer-associated venous thromboembolism. J Clin Oncol 21: 4194-4199, 2003.

48. Simpson-Haidaris PJ and Rybarczyk B: Tumors and fibrinogen. The role of fibrinogen as an extracellular matrix protein. Ann NY Acad Sci 936: 406-425, 2001.

49. Baumann $\mathrm{H}$ and Gauldie $\mathrm{J}$ : The acute phase response. Immunol Today 15: 74-80, 1994.

50. Sahni A, Simpson-Haidaris PJ, Sahni SK, Vaday GG and Francis CW: Fibrinogen synthesized by cancer cells augments the proliferative effect of fibroblast growth factor-2 (FGF-2). J Thromb Haemost 6: 176-183, 2008.

51. Rybarczyk BJ and Simpson-Haidaris PJ: Fibrinogen assembly, secretion, and deposition into extracellular matrix by MCF-7 human breast carcinoma cells. Cancer Res 60: 2033-2039, 2000.

52. Dahl M: Networking with fibrinogen: A prerequisite for fibroblast growth factor-2 (FGF-2)-stimulated tumor growth? J Thromb Haemost 6: 174-175, 2008.

This work is licensed under a Creative Commons Attribution-NonCommercial-NoDerivatives 4.0 International (CC BY-NC-ND 4.0) License. 